\title{
BMJ Open Impact of childhood experience and adult well-being on eating preferences and behaviours
}

\author{
Simon J Russell, Karen Hughes, Mark A Bellis
}

To cite: Russell SJ,

Hughes K, Bellis MA. Impact of childhood experience and adult well-being on eating preferences and behaviours. BMJ Open 2016;6:e007770. doi:10.1136/bmjopen-2015007770

- Prepublication history for this paper is available online. To view these files please visit the journal online (http://dx.doi.org/10.1136/ bmjopen-2015-007770).

Received 28 January 2015 Revised 22 September 2015 Accepted 9 October 2015

CrossMark

Centre for Public Health, Liverpool John Moores University, Liverpool, UK

Correspondence to Dr Simon J Russell; s.j.russell@ljmu.ac.uk

\section{ABSTRACT}

Objectives: To examine the relative contribution of childhood experience, measured by childhood violence and childhood happiness, and adult well-being on adult eating preferences and behaviours, independent of proximal factors such as current deprivation.

Design: A cross-sectional, stratified, randomised sample survey using retrospective measures of childhood violence and happiness and self-reported measures of current well-being.

Setting: The North West Region of England between September 2012 and March 2013.

Participants: Individuals aged 18-95-year-olds from randomly selected households (participation was successful for $90 \%$ of eligible households and $78 \%$ of the total visited addresses; $n=11243$ ).

Outcomes: Dichotomised measures for preference of healthy foods or 'feel good' foods and low or high daily fruit and vegetable consumption.

Results: After correcting for demographics, combined categories for childhood experience and dichotomised measures of adult well-being were found to be significantly related to adult food preferences and eating behaviours. Participants with unhappy and violent childhoods compared to those with happy and non-violent childhoods had adjusted ORs $(95 \% \mathrm{Cl}$, significance) of 2.67 ( 2.15 to $3.06, p<0.001)$ of having low daily fruit and vegetable intake (two or less portions) and 1.53 (1.29 to $1.81, p<0.001)$ of choosing 'feel good' foods over foods which were good for their long term health.

Conclusions: Daily intake of fruit and vegetables, linked to non-communicable diseases, and preference for 'feel good' foods, linked to obesity, are affected by childhood experience and adult well-being independent of demographic factors. Preventative interventions which support parent-child relationships and improve childhood experience are likely to reduce the development of poor dietary and other health-risk behaviours.

\section{INTRODUCTION}

In 2008, 1.5 billion men and women worldwide were overweight or obese. ${ }^{1}$ Globally, obesity has nearly doubled since $1980^{1}$ and prevalence of overweight and obesity in

\section{Strengths and limitations of this study}

- This study used data from a large established survey, with high levels of participation. The survey generated a sample with a diverse range of sociodemographics.

- The impact of childhood experience, independent of proximal factors such as current deprivation, on health behaviours has been largely unexplored. However, measures of childhood experience were retrospective and may require validation.

- Results complement existing evidence that childhood experiences impact on adult health behaviours. The burden of harms associated with health-risk behaviours, such as overeating, may be reduced with investment into further research into preventative health interventions which improve the quality of childhood experiences.

populations continues to rise. $^{2}$ Forecasts suggest that high rates of obesity will affect future populations' health and economics, ${ }^{3}$ with weight gain contributing to increases in non-communicable diseases including cardiovascular diseases, diabetes and cancers. ${ }^{2}$ In England, $62 \%$ of adults are now overweight or obese ${ }^{4}$ and the cost of overweight and obesity to the UK economy was estimated to be $£ 15.8$ billion in 2007 , including $£ 4.2$ billion in costs to the National Health Service (NHS). ${ }^{5}$ Food supply is a dominant driver of the weight gain in populations ${ }^{6}$ but frameworks for obesity determinants ${ }^{7}$ recognise layered levels of determinants where, within any given environment, propensity and resilience towards obesity varies between individuals. Eating for pleasure or hedonic eating may stimulate substantial overeating in an environment where highly palatable foods are plentiful. ${ }^{8}$ Population groups at elevated risk of obesity (those who are obese or overweight and those who have previously been obese) have been found to report greater liking for higher fat items and choose to 
consume 'feel good' foods which are high in fat or energy density. ${ }^{9}$

An important component of eating healthily is fruit and vegetables which, if consumed daily in sufficient amounts, could help prevent major diseases such as cardiovascular diseases, certain cancers, type 2 diabetes and depression. ${ }^{10}{ }^{11}$ The Joint Food and Agriculture Organization (FAO) and WHO Expert Consultation on diet, nutrition and the prevention of chronic diseases recommended the intake of a minimum of $400 \mathrm{~g}$ of fruit and vegetables per day (excluding potatoes and other starchy tubers) for the prevention of chronic diseases. ${ }^{11}$ Low fruit and vegetable intake is estimated to cause about $31 \%$ of ischaemic heart disease and $11 \%$ of strokes worldwide. ${ }^{12}$ In the UK, the mean consumption of fruit and vegetables is 4.1 portions per day $(328 \mathrm{~g})^{13}$ which is less than the European average of $386 \mathrm{~g}$ per day ${ }^{14}$ and less than the minimum consumption recommended by the FAO/WHO. There are variations in consumption of fruit and vegetables between age groups, gender, education levels, income strata, social classes and geographical regions. ${ }^{15-17}$ In terms of psychosocial correlates; low family connectedness has been demonstrated to be associated with inadequate daily fruit and vegetable consumption among adolescents. ${ }^{18}$

In addition to variation between socioeconomic gradients and other demographic factors, childhood experience plays a key role in determining adult eating preferences, behaviours and therefore body mass index (BMI). Exposure to different foods as a child can influence adult eating preferences and behaviours and therefore levels of overweight and obesity. ${ }^{19}$ Critically, children who suffer from neglect, abuse, stress and other adverse experiences are substantially more likely to suffer from childhood and adult obesity. ${ }^{19}$ Cumulative early psychological stress and increased behavioural problems have been found to be associated with childhood obesity and rapid weight gain during adolescence. ${ }^{20}$ The contribution of adverse childhoods in the creation of problem eating behaviours has been found to persist into adulthood. ${ }^{21}$ Consequently, children from neglected backgrounds are at a greatly increased risk of obesity (compared to harmonious backgrounds, OR $7.1),{ }^{22}$ while adults who suffered childhood depression have higher BMI than healthy comparisons even after accounting for demographic and social class. ${ }^{23}$

The contribution of life experiences to unhealthy eating is often confounded by demographic factors; by controlling for these factors, this study contributes to the literature on how childhood experiences and adult wellbeing influence eating preferences and behaviours. Using a large mental well-being (MWB) survey, this study seeks to identify the effect of positive and negative aspects of childhood on food choices, independent of demographic factors including deprivation and current mental well-being. Preference for 'feel good' foods rather than healthy foods and daily consumption of fruit and vegetable portions are used as measures of eating preference and behaviour; and retrospective reporting of childhood happiness and violence are used as measures of positive and negative aspects of childhood. The results are explored from a public health and a psychological perspective.

\section{METHODS}

\section{Study design and setting}

The study used data from the second repetition of the North West Mental Well-being Survey (NWMWBS) ${ }^{24}$ in the North West region of England, (population, 7056 $000) .{ }^{25}$ The target sample size was 11500 in order to provide a representative sample of the region. A clustered random approach was employed using the national Postcode Address File, which details addresses and postcodes within lower super output areas (LSOAs). Each LSOA contains approximately 1500 residents and is assigned a measure of deprivation based on 38 indicators,${ }^{26}$ as derived from the Index of Multiple Deprivation (IMD) 2010. LSOAs were randomly selected from each deprivation quintile in proportion with their occurrence for given administrative areas. A total of 21694 households were selected to account for ineligibility and non-compliance. ${ }^{27}$ A total of 14737 households were approached, $68 \%$ of selected households, before the target sample size was reached; participation was successful for $90 \%$ of eligible households and $78 \%$ of the total visited addresses. ${ }^{24}$

\section{Measures}

The structured survey included questions relating to demographics (such as gender, age and ethnicity), personal relationships, work and employment, physical health and well-being in addition to various lifestyle behaviours (such as diet and exercise). Participants were allocated a measure of deprivation based on the IMD 2010 quintile of the LSOA in which they lived. The English Indices of Deprivation are calculated from distinct domains including income, employment, education, housing, crime and living environemnt. ${ }^{28}$ Employment categories were employed (full time, parttime or self-employed), unemployed (seeking work or not seeking work for reasons of disability), full-time student, retired or other/domestic. Standard UK ethnic group categories $^{29}$ were used for the recording of ethnicity. For purposes of analyses, ethnicity was broadly categorised as White and non-Caucasian, owing to small numbers of most minority groups.

Adult MWB was measured using the standardised short Warwick-Edinburgh Mental Well-being Scale (SWEMWBS), ${ }^{30}$ an abbreviated version of the WEMWBS, which has been validated for use on adults. ${ }^{31}$ The shortened version asks participants to rate their experience on a five-point scale $(1$, none of the time; 2 , rarely; 3 , some of the time; 4 , often; 5 , all of the time) for the 2 weeks prior to participation for seven aspects of well-being (I've been feeling optimistic about the 
future; I've been feeling useful; I've been feeling relaxed; I've been dealing with problems well; I've been thinking clearly; I've been feeling close to other people; I've been able to make up my own mind about things). An overall score was calculated by summing participant scores for the seven items. For analyses, responses to questions on well-being were dichotomised with low scores $>1$ SD below the mean (MWB, mean 27.49, SD 5.05 , low $<22$ ).

Self-assessed childhood experience was measured by the question 'Overall how happy would you say your childhood was', using a 10-point scale (1=extremely happy, 10=extremely unhappy). Self-assessed childhood violence was measured in a similar way, 'Overall how violent would you say your home life as a child was? This includes violence you may have witnessed at home, not just been directly involved with' also using a 10-point scale ( $1=$ free from all violence, $10=$ very violent). Childhood measures were dichotomised to indicate relatively worse scores as approximately $>1 \mathrm{SD}$ above the mean; happy/unhappy childhoods (mean 2.79, SD 2.14, unhappy >5) and non-violent/violent childhoods (mean 1.97 , SD 1.97, violent $>4$ ). Childhood happiness and violence were highly associated (correlation coefficient 0.497, $\mathrm{p}<0.001$ ) and for the purposes of analyses, were combined into four categories happy and non-violent (83\%), unhappy but non-violent (5\%), happy but violent $(5 \%)$ and unhappy and violent $(6 \%)$.

To determine general food preference participants were asked to choose between the options of 'I prefer foods that are good for my health' and 'I prefer foods that make me feel good when I eat them'.

As an indicator of eating behaviour, participants were asked about their daily fruit and vegetable consumption: 'On a normal day, how many portions of fruit and vegetables (excluding potatoes) would you usually eat (one portion is roughly one handful or a full piece of fruit such as an apple)?', participants were asked to select either $0,1,2,3,4$ or 5 or more. For analyses, this question was divided into low (2 or less portions per day) and higher consumption (3 or more portions per day). Data for BMI were not requested from participants as self-reported weight and height have been found to be unreliable, particularly for particular population subgroups. ${ }^{32}$ For example, errors in self-reported weight have been found to increase directly with increasing levels of overweight or obesity, while errors in selfreported height have been found to increase directly with increasing age among individuals aged 45 years or over. $^{32}$

\section{Analyses}

Respondents below the age of 18 were excluded $(n=47)$ from analyses and individuals missing data on key variables were also excluded (age $n=90$, ethnicity $n=24$, childhood happiness $n=63$, childhood violence $n=67$; individuals may have missed more than one data item). The final sample was $11243 \quad(98 \%$ of all those completing the survey). Analyses were undertaken using PASW (Predictive Analytics Software) V.17.0. Statistics utilised $\chi^{2}$ for bivariate explorations of adult well-being and the combined childhood experience categories. Stratified $\chi^{2}$ was used for explorations of eating preferences and behaviours, childhood experiences and current levels of deprivation. The Mann-Whitney $\mathrm{U}$ and the Kruskal-Wallis tests were used to test the values and variance of daily fruit and vegetable consumption against high and low adult well-being and the childhood experience categories. Backwards conditional logistic regression was used to examine independent relationships between childhood experiences and adult eating behaviours. Ethical approval for the study was obtained from Liverpool John Moores University.

\section{RESULTS}

In terms of the final sample demographics, the mean age was 52.13 years (SD 19.23, range 18-95 years); $42 \%$ were male and $58 \%$ were female; and $96 \%$ were White and $4 \%$ were non-Caucasian. In terms of deprivation, $42 \%$ were from the most deprived quintile, $18 \%$ from the second most, $14 \%$ from the third most, $13 \%$ from the fourth most and $12.5 \%$ were from the least deprived quintile. In terms of childhood experience, $83 \%$ reported happy non-violent childhoods, 5\% reported unhappy non-violent childhoods, $5 \%$ reported violent but happy childhoods and $6 \%$ reported unhappy violent childhoods. In terms of adult well-being the mean score for the SWEMWBS was 27.51 (SD 5.03, range 7-35).

Food preference and daily intake of fruit and vegetables were strongly associated with a range of demographics (table 1). Preference for 'feel good' foods over healthy foods and lower intake of fruit and vegetables varied significantly with age, gender and deprivation quintile, where younger participants, male participants and more deprived participants reported less healthy preferences and behaviours. Ethnicity had no relationship with food preference but was significantly related to fruit and vegetable intake, where white participants reported consuming fewer daily portions.

There was a significant association between food preference and daily fruit and vegetable consumption (24\% of those who preferred 'feel good' foods reported low fruit and vegetable intake compared to $6 \%$ of those who reported eating foods that were good for their health, $\mathrm{p}<0.001)$. The percentage of participants who reported a preference for 'feel good' foods was significantly higher for those with low, compared to high, adult wellbeing and for those with unhappy violent childhoods, compared to happy non-violent childhoods (table 1 and figure 1A). The percentage of participants who reported low fruit and vegetable intake was $13 \%$ higher among those with low (26\%) compared to high (13\%) adult well-being, and 22\% higher for those with unhappy violent childhoods (35\%) compared to happy nonviolent childhoods (13\%; figure 1B). 


\begin{tabular}{|c|c|c|c|c|c|c|c|c|c|c|c|c|}
\hline & \multirow[b]{2}{*}{$\mathbf{n}$} & \multirow[b]{2}{*}{ Per cent } & \multicolumn{5}{|c|}{$\begin{array}{l}\% \text { preferring 'feel good' foods rather than healthy } \\
\text { foods }\end{array}$} & \multicolumn{5}{|c|}{$\begin{array}{l}\% \text { reporting low ( } \leq 2 \text { portions) daily fruit and } \\
\text { vegetable consumption }\end{array}$} \\
\hline & & & $n$ & Per cent & $\chi^{2}$ & DF & p Value & $\mathrm{n}$ & Per cent & $\chi^{2}$ & DF & p Value \\
\hline All & 11243 & 100 & 5954 & 53 & & & & 1706 & 15 & & & \\
\hline \multicolumn{13}{|l|}{ Age groups } \\
\hline $18-24$ & 975 & 9 & 622 & 64 & & & & 197 & 20 & & & \\
\hline $25-39$ & 2462 & 22 & 1466 & 60 & & & & 461 & 19 & & & \\
\hline $40-54$ & 2402 & 21 & 1287 & 54 & & & & 386 & 16 & & & \\
\hline $55-64$ & 1761 & 16 & 848 & 48 & & & & 244 & 14 & & & \\
\hline $65+$ & 3643 & 32 & 1731 & 48 & 148.836 & 4 & $<0.001$ & 418 & 11 & 85.909 & 4 & $<0.001$ \\
\hline \multicolumn{13}{|l|}{ Gender } \\
\hline Male & 4672 & 42 & 2746 & 59 & & & & 879 & 19 & & & \\
\hline Female & 6571 & 58 & 3208 & 49 & 108.624 & 1 & $<0.001$ & 827 & 13 & 82.302 & 1 & $<0.001$ \\
\hline \multicolumn{13}{|l|}{ Ethnicity } \\
\hline White & 10774 & 96 & 5706 & 53 & & & & 1668 & 15 & & & \\
\hline Non-white & 469 & 4 & 248 & 53 & 0.001 & 1 & 0.972 & 38 & 8 & 19.014 & 1 & $<0.001$ \\
\hline \multicolumn{13}{|l|}{ Deprivation quintile } \\
\hline (least deprived) 1 & 1410 & 13 & 514 & 36 & & & & 94 & 67 & & & \\
\hline 2 & 1501 & 13 & 652 & 43 & & & & 153 & 10 & & & \\
\hline 3 & 1566 & 14 & 770 & 49 & & & & 195 & 12 & & & \\
\hline 4 & 2042 & 18 & 1148 & 56 & & & & 292 & 14 & & & \\
\hline (most deprived) 5 & 4724 & 42 & 2870 & 61 & 341.749 & 4 & $<0.001$ & 972 & 21 & 225.532 & 4 & $<0.001$ \\
\hline \multicolumn{13}{|l|}{ Adult well-being } \\
\hline High & 9736 & 87 & 5043 & 52 & & & & 1309 & 13 & & & \\
\hline Low & 1507 & 13 & 911 & 60 & 39.229 & 1 & $<0.001$ & 397 & 26 & 168.687 & 1 & $<0.001$ \\
\hline \multicolumn{13}{|l|}{ Childhood experience } \\
\hline Happy non-violent & 9378 & 83 & 4846 & 52 & & & & 1245 & 13 & & & \\
\hline Unhappy non-violent & 605 & 5 & 329 & 54 & & & & 124 & 21 & & & \\
\hline Happy violent & 545 & 5 & 302 & 55 & & & & 89 & 16 & & & \\
\hline Unhappy violent & 715 & 6 & 477 & 67 & 62.318 & 3 & $<0.001$ & 248 & 35 & 251.604 & 3 & $<0.001$ \\
\hline
\end{tabular}



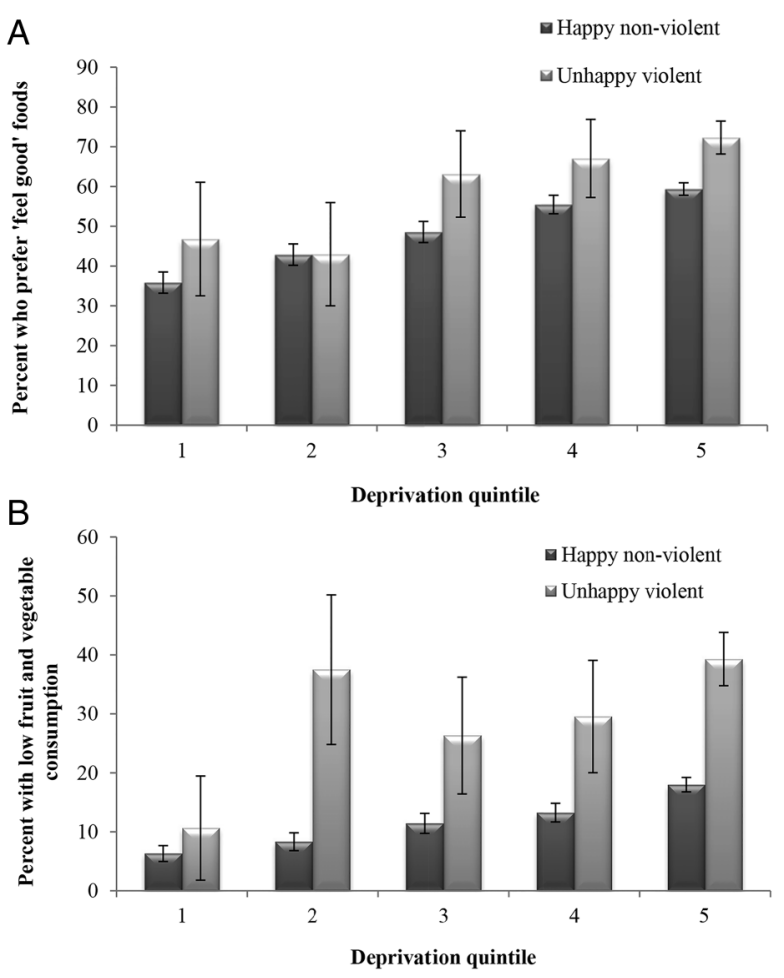

Figure 1 (A) Preference for 'feel good' foods by current level of deprivation and childhood experience, with $95 \%$ Cls. Happy non-violent childhood ( $n=9378$ ), unhappy violent childhood $(n=715)$; Pearson $\chi^{2}$ found the overall trend to be highly significant $\left(\chi^{2}=60.285\right.$, sig<0.001). (B) Low fruit and vegetable consumption ( $\leq 2$ portions per day) by current level of deprivation and childhood experience, with $95 \%$ Cls. Happy non-violent childhood ( $n=9378)$, unhappy violent childhood $(n=715)$. Pearson $\chi^{2}$ found the overall trend to be highly significant $\left(\chi^{2}=241.598\right.$, sig<0.001).

The median value for daily fruit and vegetable consumption across all categories was four, with the exception of participants with low adult well-being and unhappy violent childhoods where the median values were three. The differences in daily fruit and vegetable consumption between high and low adult well-being $(\mathrm{Z}=$ $-16.908, \mathrm{p}<0.001)$ and the childhood experience categories $\left(\chi^{2}=219.910, p<0.001\right)$ were highly significant.

Backwards conditional logistic regression analyses were applied to independently examine the effects of adult well-being and childhood experience on eating preferences and behaviours, while controlling for the effects of demographics (table $2^{\mathrm{i}}$ ). All relationships for adult well-being and childhood experience were significant $(p<0.001)$. Low fruit and vegetable intake showed the greatest increases in adjusted odds for low adult wellbeing and unhappy violent childhoods. Compared with high adult well-being, adjusted odds of low fruit and vegetable intake were 1.81 (95\% CIs 1.58 to 2.08$)$ in

${ }^{\mathrm{i}}$ Unadjusted odds ratios were also calculated to indicate the associations for given groups without controlling for other factors. those with low adult well-being. Compared with those reporting happy non-violent childhoods, adjusted odds of low fruit and vegetable intake were 2.57 (95\% CIs 2.15 to 3.06) in those with unhappy violent childhoods and 1.58 (95\% CIs 1.28 to 1.95 ) for those with unhappy non-violent childhood, although the group of happy violent childhoods was not significant. Compared with happy non-violent childhoods, adjusted odds of preferring 'feel good' foods were 1.53 (95\% CIs 1.29 to 1.80 ) in those with unhappy violent childhoods. Compared with high adult well-being adjusted odds of preferring 'feel good' foods were 1.24 (95\% CIs 1.11 to 1.39 ) in those with low adult well-being.

\section{DISCUSSION}

The links between obesity and eating for pleasure $^{9}$ and the links between a range of health risks and low fruit and vegetable consumption ${ }^{10}{ }^{11}$ have been extensively demonstrated. While associations between social deprivation and obesity in the UK have been identified, ${ }^{33}$ a key aim of this research was to examine the association between childhood experience and adult well-being independent of demographic factors, including current level of deprivation. For example, among those in the most deprived quintile, low daily fruit and vegetable consumption was more than doubled in those reporting unhappy and violent childhoods (39\%) compared with those with happy and non-violent childhoods (18\%; figure 1B). After accounting for current level of deprivation, analyses revealed that adults with low well-being and those that suffered adverse childhood experiences were significantly more inclined to eat for pleasure rather than for the good of their health and more likely to consume lower levels of daily fruit and vegetable portions. Since childhood experience is a determinant of adult well-being, ${ }^{34}$ the association between childhood experience and adult eating preferences, behaviours and therefore propensity for obesity may be even greater than indicated by these results.

A variety of theories consistent with our findings connect childhood experiences with adult eating behaviours. There is increasing evidence for chronic stress during childhood causing maladaptive brain development with an array of negative consequences. These include impacts on the plastic processes of brain development, emotional regulation, cognitive response, memory and learning ${ }^{35}$ and autonomic, endocrine and immune systems. ${ }^{36}$ Children exposed to adverse conditions are also at significantly increased risk of a range of mental and emotional problems including depression and anxiety disorders, ${ }^{37}$ and some individuals respond to such states with excessive eating. ${ }^{38}$ Links between emotional distress and overeating, ${ }^{39}$ and between emotional overeating and depression, ${ }^{40}$ have been reported. Negative moods and stress are the most frequently cited precipitants of binge eating. ${ }^{41}$ The neurobiology of stress is also interlinked with that of energy regulation 
Table 2 Changes in odds and adjusted odds of 'feel good' food choices and low fruit and vegetable consumption with childhood happiness, violence and demographic factors

\begin{tabular}{|c|c|c|c|c|c|c|c|c|}
\hline & \multicolumn{4}{|c|}{ Eating for pleasure rather than health } & \multicolumn{4}{|c|}{$\begin{array}{l}\text { Low fruit and vegetable consumption } \\
\text { ( } \leq 2 \text { portions/day) }\end{array}$} \\
\hline & OR & AOR $^{*}$ & 95\% Cls & p Value & $\overline{\text { OR }}$ & AOR $^{*}$ & 95\% Cls & p Value \\
\hline Age & & & & $<0.001$ & & & & $<0.001$ \\
\hline $18-24$ & 1.946 & 1.786 & 1.537 to 2.075 & $<0.001$ & 1.954 & 1.821 & 1.500 to 2.210 & $<0.001$ \\
\hline 25-39 & 1.625 & 1.522 & 1.367 to 1.694 & $<0.001$ & 1.777 & 1.615 & 1.390 to 1.875 & $<0.001$ \\
\hline $40-54$ & 1.275 & 1.210 & 1.088 to 1.345 & $<0.001$ & 1.477 & 1.354 & 1.161 to 1.579 & $<0.001$ \\
\hline $\begin{array}{l}55-64 \\
\text { (Ref) } 65+\end{array}$ & 1.025 & 0.986 & 0.877 to 1.108 & 0.810 & 1.241 & 1.179 & 0.991 to 1.402 & 0.063 \\
\hline \multicolumn{9}{|l|}{ Gender } \\
\hline $\begin{array}{l}\text { Male } \\
\text { (Ref) Female }\end{array}$ & 1.495 & 1.554 & 1.438 to 1.680 & $<0.001$ & 1.601 & 1.685 & 1.515 to 1.875 & $<0.001$ \\
\hline \multicolumn{9}{|l|}{$\begin{array}{l}\text { Ethnicity } \\
\text { (Ref) White }\end{array}$} \\
\hline Non-Caucasian & 0.997 & 0.721 & 0.595 to 0.873 & 0.001 & 0.481 & 0.336 & 0.238 to 0.474 & $<0.001$ \\
\hline $\begin{array}{l}\text { Deprivation quintile } \\
\text { (Ref) (least deprived) } 1\end{array}$ & & & & $<0.001$ & & & & $<0.001$ \\
\hline 2 & 1.339 & 1.330 & 1.144 to 1.547 & $<0.001$ & 1.589 & 1.538 & 1.173 to 2.016 & 0.002 \\
\hline 3 & 1.686 & 1.651 & 1.423 to 1.917 & $<0.001$ & 1.991 & 1.870 & 1.441 to 2.428 & $<0.001$ \\
\hline 4 & 2.239 & 2.194 & 1.905 to 2.527 & $<0.001$ & 2.337 & 2.199 & 1.720 to 2.813 & $<0.001$ \\
\hline (most deprived) 5 & 2.699 & 2.514 & 2.216 to 2.852 & $<0.001$ & 3.627 & 3.124 & 2.495 to 3.912 & $<0.001$ \\
\hline \multicolumn{9}{|l|}{$\begin{array}{l}\text { Adult well-being } \\
\text { (Ref) High }\end{array}$} \\
\hline Low & 1.422 & 1.240 & 1.105 to 1.392 & $<0.001$ & 2.303 & 1.812 & 1.580 to 2.077 & $<0.001$ \\
\hline $\begin{array}{l}\text { Childhood experience } \\
\text { (Ref) Happy non-violent }\end{array}$ & & & & $<0.001$ & & & & $<0.001$ \\
\hline Unhappy non-violent & 1.115 & 1.097 & 0.926 to 1.301 & 0.284 & 1.684 & 1.579 & 1.275 to 1.954 & $<0.001$ \\
\hline Happy violent & 1.162 & 1.028 & 0.860 to 1.229 & 0.758 & 1.275 & 1.065 & 0.837 to 1.356 & 0.608 \\
\hline Unhappy violent & 1.874 & 1.530 & 1.294 to 1.808 & $<0.001$ & 3.469 & 2.568 & 2.154 to 3.062 & $<0.001$ \\
\hline
\end{tabular}

and appetite, and is a key risk factor in the development of addiction. ${ }^{42}$ Stress during childhood or adulthood can augment the consumption of 'feel good' foods, which increases the salience of such foods and can lead to weight gain. ${ }^{42}$ Reward pathways associated with stress and the consumption of 'feel good' foods can increase motivation, which can increase the risk of developing addictive behaviours.

Availability of food is also a determinant of the quality and quantity of food eaten by humans ${ }^{43}$ and a dominant driver of obesity. ${ }^{6}$ In the presence of high food availability, weight regulation requires higher cognitive control since psychological and behavioural factors urge an individual to eat. ${ }^{44}$ Those that suffer early life stress, such as abuse and neglect, may be inhibited in the development of higher order, complex cognitive and affective functions associated with brain regions which undergo protracted postnatal development. ${ }^{45}$ These findings are consistent with previous research which indicates that a significantly higher number of obese individuals engaged with weight loss programmes had suffered adverse childhood experiences ${ }^{37}$ and evidence that patients with binge eating disorder frequently suffer from psychopathology, including unhealthy restraint and psychological distress, such as depression. ${ }^{46}$ Adverse experiences and stress during formative periods of development may affect eating preferences and behaviours into adulthood, independent of MWB and current level of deprivation and with detrimental effects, including overweight or obesity.

Public health interventions for obesity are frequently aimed at adults but evidence of how diet can be moderated at that stage is unclear. Interventions with children often focus on education about diet but recognition of the link between early life experiences and adult eating behaviours may provide wider avenues for preventative interventions. Our findings suggest that public health approaches that seek to improve childhood experiences, most notably by supporting parent-child relationships, may be particularly cost-effective owing to their potential of reducing the development of various health-risk behaviours. ${ }^{47}$

Further research is required to determine at what stage of development the influence of early life stress begins to manifest behavioural change leading to overweight and obesity. Better understanding is also required of when and in which cases causing or allowing children to become overweight or obese may constitute child neglect or abuse. The relationship between childhood neglect and adult overweight appears to be stronger than the effects of hedonic eating and inadequate consumption of fruit and vegetables. Therefore further 
research is also required to identify the other factors in this relationship, which may include reduced food quality, fewer family meals and increased passive time, all of which may be coincident with neglectful homes.

\section{Limitations}

Measures of general eating preference and daily consumption of fruit and vegetables were used rather than BMI, for which self-reporting is unreliable $;{ }^{32}$ however, these indicators may also be subject to inaccuracies. While previous piloting of the question to measure general eating preference indicated a level of reliability, some participants might 'feel good' when they eat healthy foods or believe that their diet is healthy when it is not; similarly participants may misunderstand what constitutes a portion of fruit or vegetables. The relationship between childhood experience and adult well-being may also be subject to some inaccuracy since the association is closely linked and there may be some reporting bias. The measures for childhood experience were retrospective and adults suffering with low or high adult well-being may recall their childhoods with distortion; a wider range of validated questions would assist in reducing the potential inaccuracies. The dependent variables were dichotomised (for adult wellbeing) or combined into four groups (for childhood happiness and violence) for analyses. While combining the data in this way could lead to a loss of information, the objective of the study was to examine the effect of low adult well-being and adverse childhood experience on poor diet choices and inadequate fruit and vegetable consumption. The categorisation of low adult well-being used a measure of less than one SD below the mean and the highly significant association of childhood happiness and violence justified their combination.

\section{CONCLUSIONS}

Empirical evidence that demonstrates effective interventions for overweight and obese children and adults is limited and prevention efforts have rarely been sustained. ${ }^{3}$ Results here suggest that low daily intake of fruit and vegetables, linked to non-communicable diseases, and preference for 'feel good' foods, linked to obesity, are affected by childhood experience and adult wellbeing independent of demographic factors. Preventative interventions which support parent-child relationships and improve childhood experience are likely to reduce the development of poor dietary and other health-risk behaviours. Such prevention and support would require a multiagency approach, with coordination from domestic violence, parenting, developmental and school services. Obesity treatments for adults may also benefit by incorporating mental health elements to improve current psychological functioning and subjective wellbeing, which may enable healthier eating and sustained weight loss.

Acknowledgements The authors would like to thank the members of the North West Mental Wellbeing Survey Steering Group for their valuable support, advice and direction on this work. The authors are particularly grateful to Alyson Jones and Clare Perkins from the Knowledge and Intelligence Team North West, Public Health England for their advice and support. The authors also recognise the contributions of the local authorities and primary care trusts who commissioned the mental well-being survey and all those individuals who gave up their time to participate.

Contributors SJR was the primary author and led the analysis and interpretation of the work. $\mathrm{KH}$ was involved in the design of the work and was responsible for editing and revising the original draft. MAB led the conception of the work and was responsible for editing and revising the final draft.

Funding This research received no specific grant from any funding agency in the public, commercial or not-for-profit sectors.

Competing interests None declared.

Ethics approval Liverpool John Moores University Research Ethics Committee.

Provenance and peer review Not commissioned; externally peer reviewed.

Data sharing statement No additional data are available.

Open Access This is an Open Access article distributed in accordance with the Creative Commons Attribution Non Commercial (CC BY-NC 4.0) license, which permits others to distribute, remix, adapt, build upon this work noncommercially, and license their derivative works on different terms, provided the original work is properly cited and the use is non-commercial. See: http:// creativecommons.org/licenses/by-nc/4.0/

\section{REFERENCES}

1. World Health Organization. Obesity and overweight Fact sheet N³11. Updated March 2013. http://www.who.int/mediacentre/ factsheets/fs311/en/ (accessed 7 Nov 2013).

2. Wang YC, McPherson $\mathrm{K}$, Marsh $\mathrm{T}$, et al. Health and economic burden of the projected obesity trends in the USA and the UK. Lancet 2011;378:815-25.

3. Gortmaker SL, Swinburn BA, Levy D, et al. Changing the future of obesity: science, policy, and action. Lancet 2011;378:838-47.

4. Department of Health. Policy: Reducing obesity and improving diet. Published 25 March 2013. https://www.gov.uk/government/policies/ reducing-obesity-and-improving-diet\#issue (accessed 12 Nov 2013).

5. Public Health England. Obesity and health. 2013a. http://www.noo. org.uk/NOO_about_obesity/obesity_and_health (accessed 12 Nov2013).

6. Swinburn B, Sacks G, Ravussin E. Increased food energy supply is more than sufficient to explain the US epidemic of obesity. Am J Clin Nutr 2009:90:1453-6.

7. Kumanyika S, Jeffery RW, Morabia A, et al, Public Health Approaches to the Prevention of Obesity (PHAPO) Working Group of the International Obesity Task Force (IOTF). Obesity prevention: the case for action. Int J Obes Relat Metab Disord 2002;26:425-36.

8. Monteleone P, Piscitelli F, Scognamiglio P, et al. Hedonic eating is associated with increased peripheral levels of ghrelin and the endocannabinoid 2-arachidonoyl-glycerol in healthy humans: a pilot study. J Clin Endocrinol Metab 2012:97:E917-24.

9. Nasser J. Taste, food intake and obesity. Obes Rev 2001;2:213-18.

10. Harding $\mathrm{AH}$, Wareham NJ, Bingham SA, et al. Plasma vitamin $\mathrm{C}$ level, fruit and vegetable consumption, and the risk of new-onset type 2 diabetes mellitus: the European prospective investigation of cancer-Norfolk prospective study. Arch Intern Med 2008;168.14:1493-9.

11. World Health Organization. Diet, Nutrition and the Prevention of Chronic Diseases. Report of a Joint WHO/FAO Expert Consultation. WHO Technical Report Series No. 916. Geneva, 2008.

12. World Health Organization. The World Health Report 2002, Reducing risks, promoting health. Geneva, 2002.

13. Department of Health. Statistical Press Notice: National Diet and Nutrition Survey: headline results from years 1, 2 and 3 combined (2008/09-2010/11). Published 2012. https://www.gov.uk/ government/news/statistical-press-notice-national-diet-and-nutritionsurvey-headline-results-from-years-1-2-and-3-combined-2008-092010-11 (accessed 8 Nov 2013).

14. European Food Safety Authority. Concise Database summary statistics-Total population. 2008. http://www.efsa.europa.eu/en/ datexfoodcdb/datexfooddb.htm (accessed 02 Dec 2013). 
15. Johansson L, Andersen LF. Who eats 5 a day? Intake of fruits and vegetables among Norwegians in relation to gender and lifestyle. $J$ Am Diet Assoc 1998;6:689-91.

16. Ministry of Agriculture, Fisheries and Food. National Food Survey 1998. London: The Stationery Office, 1999.

17. Thompson RL, Margetts BM, Speller VM, et al. The Health Education Authority's health and lifestyle survey 1993: who are the low fruit and vegetable consumers? J Epidemiol Commun Health 1999;53:294-9.

18. Neumark-Sztainer D, Story M, Resnick MD, et al. Correlates of inadequate fruit and vegetable consumption among adolescents. Prev Med 1996;25:497-505

19. Ebbeling CB, Pawlak DB, Ludwig DS. Childhood obesity: public-health crisis, common sense cure. Lancet 2002;360:473-82.

20. Koch FS, Sepa A, Ludvigsson J. Psychological stress and obesity. J Pediatr 2008;153:6.

21. Johnson JG, Cohen P, Kasen S, et al. Childhood adversities associated with risk for eating disorders or weight problems during adolescence or early adulthood. Am J Psychiatry 2002;159:394-400.

22. Lissau I, Sorensen TIA. Parental neglect during childhood and increased risk of obesity in young adulthood. Lancet 1994;343:324-7.

23. Pine DS, Goldstein RB, Wolk S, et al. The association between childhood depression and adult body mass index. Pediatrics 2001;107:1049-56.

24. Public Health England. North West Mental Wellbeing Survey 2012 13. PHE publications gateway number: (2013b) 2013240.

25. Office for National Statistics. Population estimates for England and Wales, mid-2011 (2011 Census-based). http://www.ons.gov.uk/ons/ publications/re-reference-ables.html?edition=tcm\%3A77-262039 (accessed 21 Jun 2013).

26. Department for Communities and Local Government. English indices of deprivation 2010. London: Department for Communities and Local Government, 2011.

27. Bellis MA, Lowey $\mathrm{H}$, Hughes $\mathrm{K}$, et al. Variations in risk and protective factors for life satisfaction and mental wellbeing with deprivation: a cross-sectional study. BMC Public Health 2012;12:492.

28. English indices of deprivation. Department for Communities and Local Government. 2010. https://www.gov.uk/government/statistics/ english-indices-of-deprivation-2010 (accessed 15 Apr 2013).

29. Office for National Statistics. Census 2001. http://www.ons.gov.uk ons/guide-method/census/census-2001/about-census-2001/ census-2001-forms/index.html (accessed 21 Jun 2013).

30. Stewart-Brown S, Tennant A, Tennant R, et al. Internal construct validity of the Warwick-Edinburgh Mental Well-being Scale (WEMWBS): a Rasch analysis using data from the Scottish Health Education Population Survey. Health Qual Life Outcomes 2009;7:15.

31. Well Scotland. Resources: The Warwick-Edinburgh Mental Wellbeing Scale. 2011. http://www.wellscotland.info/guidance/
How-to-measure-mental-wellbeing/How-to-start-measuringmental-wellbeing/The-Warwick-Edinburgh-Mental-Wellbeing-Scale (accessed 20 Jan 2013).

32. Rowland NL. Self-reported weight and height. Am J Clin Nutr 1990;52:1125-33.

33. Kinra S, Nelder RP, Lewendon GJ. Deprivation and childhood obesity: a cross sectional study of 20973 children in Plymouth, United Kingdom. J Epidemiol Commun Health 2000;54:456-60.

34. Bellis MA, Hughes $\mathrm{K}$, Jones $\mathrm{A}$, et al. Childhood happiness and violence: a retrospective study of their impacts on adult well-being BMJ Open 2013;3:e003427.

35. Anda RF, Felitti VJ, Bremner JD, et al. The enduring effects of abuse and related adverse experiences in childhood: a convergence of evidence from neurobiology and epidemiology. Eur Arch Psychiatry Clin Neurosci 2006;256:174-86.

36. Heim C, Nemeroff CB. The role of childhood trauma in the neurobiology of mood and anxiety disorders: preclinical and clinical studies. Biol Psychiatry 2001;49:1023-39.

37. Gustafson TB, Sarwer DB. Childhood sexual abuse and obesity. Obes Rev 2004;5:129-35.

38. Bruch H. Psychological aspects in overeating and obesity. Psychosomatics 1964;5:269-74.

39. Felitti VJ. Childhood sexual abuse, depression and family dysfunction in adult obese patients: a case control study. South Med $J$ 1993;86:732-6.

40. Masheb RM, Grilo CM. Emotional overeating and its associations with eating disorder psychopathology among overweight patients with Binge eating disorder. Int J Eat Disord 2006;39:141-6.

41. Polivy J, Herman CP. Etiology of binge eating: psychological mechanisms. In: Fairburn CF, Wilson GT, eds. Binge eating: nature, assessment and treatment. New York: Guilford Press, 1993:173-205.

42. Sinha R, Jastreboff AM. Stress as a common risk factor for obesity and addiction. Biol Psychiatry 2013;73:827-35.

43. Mela D. Eating behaviour, food preferences and dietary intake in relation to obesity and body-weight status. Proc Nutr Soc 1996;55:803-16.

44. Ulijaszek SJ. Human eating behaviour in an evolutionary ecological context. Proc Nutr Soc 2002;61:517-26.

45. Pechtel P, Pizzagalli DA. Effects of early life stress on cognitive and affective function: an integrated review of human literature. Psychopharmacology (Berl) 2011;214:55-70.

46. Johnson JG, Spitzer RL, Williams JBW. Health problems impairment and illness associated with bulimia nervosa and binge eating disorder among primary care and obstetric gynaecology patients. Psychol Med 2001;31:1455-66.

47. Chartier MJ, Walker JR, Naimark B. Health risk behaviors and mental health problems as mediators of the relationship between childhood abuse and adult health. Am J Public Health 2009;99:847-54. 